\title{
Effective Point of Measurement (EPOM) of Some Ionization Chambers for High Energy Photon Beam Dosimetry used in Radiotherapy for the Treatment of Cancer Patient
}

\author{
Nadia Akter Mokta ${ }^{1}$, Md Shakilur Rahman ${ }^{2 *}$, Tanjim Siddiqua ${ }^{2}$, Santunu Purohit ${ }^{1}$, Md Kawchar \\ Ahmed Patwary ${ }^{3}$, Akm Moinul Haque Meaze ${ }^{1}$ and Humayra Ferdous ${ }^{4}$ \\ ${ }^{1}$ Department of Physics, University of Chittagong, Chittagong 4331, Bangladesh
}

${ }^{2}$ Secondary Standard Dosimetry Laboratory, Bangladesh Atomic Energy Commission, Savar, Dhaka-1349, Bangladesh

${ }^{3}$ Department of Physics, Comilla University, Comilla 3506, Bangladesh

${ }^{4}$ Department of Physics, American International University Bangladesh, Dhaka, Bangladesh

*Corresponding author: Shakilur Rahman, Secondary Standard Dosimetry Laboratory, Bangladesh Atomic Energy Commission, Savar, Dhaka, Bangladesh

\section{ARTICLE INFO}

Received: 慧 August 26, 2019

Published: 幽 August 30, 2019

Citation: Nadia Akter Mokta, Md Shakilur Rahman, Tanjim S, Santunu P, Md Kawchar Ahmed P, et al., Effective Point of Measurement (EPOM) of Some Ionization Chambers for High Energy Photon Beam Dosimetry used in Radiotherapy for the Treatment of Cancer Patient. Biomed J Sci \& Tech Res 21(1)-2019. BJSTR. MS.ID.003539.
ABSTRACT

The volumetric effect occupied by the air cavity for the dosimetry of high energy photon beam is impossible to ignore using standard ionization chambers. Hence, the dose measurement should be corrected with a displacement perturbation correction factor $\left(\mathrm{P}_{\text {dis }}\right)$ or using an Effective Point of Measurement (EPOM). The aim of this study was to calculate the EPOM of some ionization chambers and evaluation of the shift of EPOM that recommended by various international protocols under both reference and non-reference condition. The work was performed with Percentage Depth Dose (PDD) curves by placing chambers (PTW 30013, FC 65G and Semiflex 31010) at the geometrical centers for field size(s) of $5 \mathrm{~cm} \times 5 \mathrm{~cm}$ to $30 \mathrm{~cm} \times 30 \mathrm{~cm}$ at $100 \mathrm{~cm}$ Source to Surface Distance (SSD) for photon energy 6,10 and 15MV respectively. The shift of the cylindrical chambers also estimated from PDD values in comparison with reference PDD values by Parallel Plate Chamber (PPC 40 and Murkus 23343) of 100\%, 80\% and 50\% depth in the water. The present study shows that the effective shift is not only varies with chamber materials but also with photon energy. On the other hand the periodical calibration factor of some ionization chambers at standard procedures were compared with manufacturer values also varies with time which is an important issues for the precisional dosimetry in radiotherapy. The details of the EPOM and chamber calibration factor is discussed.

Abbreviations: EPOM: Effective Point of Measurement; TRS: Technical Report Series; PDD: Percentage of Depth Dose; TG: Task Group; SSD: Source to Surface Distance

\section{Introduction}

Cancer is a serious health issue and be a principle determinant of the human and economic wealth in a country. It is a malignant tumor or an overgrowth of abnormal cells. Its two main characteristics are uncontrolled growth of the cells in the human body and the ability of these cells to migrate from the original site and invade or spread to distant sites or other parts of the body. The motive of illuminating malignant tumor is to deliver a sufficient radiation dose to the target volume. However, it is impossible to illuminate only tumor cells. If we deliver low dose, the treatment will be failed while a high dose will damage the normal cells. In radiotherapy various quality assurance $(\mathrm{QA})$ and quality control $(\mathrm{QC})$ parameters are indispensable for the success of tumor eradication. The realistic goal of radiation therapy is to maximize the dose to abnormal cells while minimizing exposure to normal cells and spring the surrounding healthy tissues as much as possible. According to the formulation of the cavity theory, the walls of ionization chambers should be water equivalent [1]. However, even if the chamber wall is 
medium equivalent, the volume of water is replaced with the cavity of a cylindrical ionization chamber when the reference point of the chamber at the chamber axis is placed at the depth of measurement.

This effect is taken into account by the displacement correction factor, $\mathrm{P}_{\text {dis }}$ or by placing the Effective Point of Measurement (EPOM) of the chamber at the measuring depth. Generally, the EPOM depends on the chamber design including the cavity height and radius, the mass density of the wall material of central electrode, and some other parameters. For instance, the factor, $\mathrm{P}_{\text {dis }}$ is used in the international code of practice IAEA TRS-398 (IAEA 2000) [2] and the EPOM for instance in the German dosimetry protocol DIN 6800-2 (DIN 2008) [3].

For reference dosimetry in clinical photon beams, most dosimetry protocols recommend the application of a perturbation correction $\mathrm{P}_{\text {dis }}$ but only the German protocol DIN 6800-2 applies the EPOM concept for all types of measurements. The distance between the central axis and the EPOM is termed as the EPOM shift. The EPOM shift is obtained by a shift factor multiplied by the inner chamber radius. According to chamber radius for different energies, the dosimetry protocols have expressed effective point value recently. In IAEA TRS-398, the shift equal to $0.6 \mathrm{r}$ ( $\mathrm{r}$ being the radius of the chamber) mean before recommended for ${ }^{60} \mathrm{Co} \gamma$-rays and all high energy photon beams whereas $0.5 \mathrm{r}$ for electron beams [4].

However, it has been shown that, the experimental evidence and Monte Carlo simulations on the magnitude of the shift $0.6 \mathrm{r}$ is not always correct. The EPOM of cylindrical ionization chamber in megavoltage photon beams has already been evaluated using Monte Carlo simulation with the EGSnrc system [5]. But it is too large for thimble ion chambers in high energy photon beams [6] and can also design for a thimble ionization chamber with zero EPOM by adjusting the wall thickness of chamber [7]. Moreover, the systematic dependence on chamber characteristics provides evidence that a universal parameterization in terms of a few design parameters is conceivable and has implication for the calculation of chamber correction factors.

Therefore, there is some possibility that the experimental results and Monte Carlo derived values do not always same. That's why there is an argument on which correction factor should be given preference although the uncertainties involved in this. Because the uncertainties do not give any decision on this, it only reduces the range for the correct value. The application of the proposed effective point of measurement will increase the accuracy of calculating depth dose data from measured depth ionization curves, especially for depth beyond the reference depth. So, the main objectives of this study are quality control for ionization chambers based on absorbed dose measurements by determining the EPOM of some ionization chambers and evaluation of the shift of EPOM that recommended by various international protocol.

\section{Materials and Methods}

\section{Ionization Chamber}

In modern radiation therapy clinics, ionization chambers are the detectors of choice for calibrating the output of radiation therapy treatment machines. An ionization chamber is used to measure the rate of radiation exposure (how much radiation exposure is being received in a specified period of time).In this study nine ionization chambers are used; six for calibration (chamber model TW 30013, TW 31014, TW 30013, Exradin A19 of each respectively and two TW 31010) and three for determination of effective point of measurement (chamber model - Semiflex 31010, PTW-30013, FC 65G). In addition, with the above nine chambers, some reference standard chambers were used where one (chamber model - NE 2571) for calibration and two (chamber model - Murkus 23343 and PPC 40) for effective point of measurements.

\section{Calibration of Ionization Chamber}

Calibration of the ionization chambers used in radiotherapy, were performed in comparison with the Secondary Standard Dosimetry Laboratory (SSDL) reference or working standard ionization chambers of Bangladesh Atomic Energy Commission which is the part of IAEA/WHO SSDL network, by using substitution method. Calibrations in terms of absorbed dose to water were carried out for ${ }^{60} \mathrm{Co}$ gamma ray beam of a teletherapy unit which was performed for field chambers of various radiotherapy centers (Delta Medical Hospital Limited, Dhaka; Khawja Yunus Ali Medical College and Hospital, Sirajgonj). When calibrating in terms of absorbed dose to water, the chamber protected by a PMMA sleeve, was positioned in a $30 \mathrm{~cm} \times 30 \mathrm{~cm} \times 30 \mathrm{~cm}$ water phantom so that its reference point was on the central axis of the beam. The chamber axis was perpendicular to the central axis of the beam and the distance from the source to the reference point of the chamber was $80 \mathrm{~cm}$. The reference point of the chamber was at $5 \mathrm{~cm}$ water depth and the size of the radiation field (50\% isodose level) at the reference plane was $10 \mathrm{~cm} \times 10 \mathrm{~cm}$.

The absorbed dose to water $\left(D_{w}\right)$ was calculated by the following equation [4]

$$
N_{D, W}=\frac{D_{W}\left(Z_{r e f}\right)}{M_{Q}} ;\left(\frac{G y}{C}\right) \ldots \ldots . .(1)
$$

Where, $\mathrm{N}_{\mathrm{D}, \mathrm{w}}$ is the calibration factor, $\mathrm{D}_{\mathrm{W}}\left(\mathrm{Z}_{\text {ref }}\right)$ is the measured absorbed dose to water ( $\mathrm{Gy} / \mathrm{min}$ ) at reference position by reference ionization chamber and $\mathrm{M}_{\mathrm{Q}}$ be the measured charge (nC/min) corrected for ambient condition, polarity and ion recombination correction factors (temperature and pressure) by this equation:

$$
M_{Q}=m_{\text {raw }} \times k_{t p} \times k_{\text {elec }} \times k_{\text {pot }} \times k_{s} \ldots \ldots \ldots
$$

Where, $\mathrm{m}_{\text {raw }}$ is uncorrected electrometer reading and $\mathrm{k}_{\mathrm{tp}}, \mathrm{k}_{\text {elec' }}$ $\mathrm{k}_{\mathrm{pol}}$ and $\mathrm{k}_{\mathrm{s}}$ are correction factors for temperature and pressure, the electrometer, polarity and ion recombination respectively. 


\section{Determination of Effective Point of Measurement}

In the present study the effective point of PTW 30013, FC65-G and Semiflex-31010 ionization chambers has been measured by using two medical linear accelerators (Clinac Ix and 2300C/D from Varian) of National Institute of Cancer Research \& Hospital, Mohakhali, Dhaka and North East Medical College \& Hospital, Sylhet by PDD curve.

Reference Depth-Ionization Curve for Photon Beams: Two types of chambers, plane parallel plate (PPC 40 and Murkus 23343) and cylindrical (PTW 30013-364, FC 65G and Semiflex 31010) were used for determination EPOM. For parallel-plate chambers, the EPOM is known and its experimental values are found in the literature. Both the parallel plate ionization chambers are Murkus type and its experimental effective point are at $1 \mathrm{~mm}$ depth from entrance surface. The PPC 40 and Murkus 23343 chambers were used to measure at a high precision depth-ionization curve as a reference curve so in order to measure the EPOM of unknown cylindrical chambers, (i) PDD data were measured using plane parallel chamber of known EPOM (1 $\mathrm{mm}$ from entrance surface) then (ii) the same PDD measured for cylindrical chamber at geometrical point.

The measurements for the photon beams were performed in a water phantom using the commercial beam analyzer system MP3-M (PTW, Freiburg). Field size $5 \mathrm{~cm} \times 5 \mathrm{~cm}$ to maximum $30 \mathrm{~cm}$ $\times 30 \mathrm{~cm}$ were taken for depths measurement in the range of 0 to $300 \mathrm{~mm}$. A spirit level was used to ensure that the phantom axes were correctly aligned. The scanning direction was taken from the bottom towards the water surface with a step of $1 \mathrm{~mm}$ and from the water surface to the bottom with a step of $3 \mathrm{~mm}$ in the region of interest. A second chamber (cylindrical chamber) served as the reference or monitoring ionization chamber. Measured data were evaluated and analyzed by the software MEPHYSTO mc ${ }^{2}$ (PTW, Freiburg) [8]. The readings were normalized to the maximum dose.

PDD Curve: Relative dosimetry was carried out by positioning the chambers perpendicular to the photon beam. By using different ionization chambers percent depth dose (PDD) curves are obtained. The PDD was measured for different field sizes $(5 \mathrm{~cm} \times$ $5 \mathrm{~cm}$ to maximum $30 \mathrm{~cm} \times 30 \mathrm{~cm}$ ) at $100 \mathrm{~cm}$ SSD for various photon energy 6, 10, 15MV. By comparing PDD by both types of chamber, the displacements of the cylindrical chambers were calculated for $100 \%, 80 \%$ and $50 \%$ inside the water.

Parameters Used to Determine the EPOM Shift: The standardization of radiotherapy beam output by means of absorbed dose to water is measured with cylindrical and parallel plate ionization chamber. The measurement is performed inside a water phantom. The effective point of measurement (EPOM) accounts for the effect of replacing a volume of water by the ionization chamber when the reference point of the chamber is positioned at depth inside the water phantom. The absorbed dose to water at any depth ' $\mathrm{Z}$ ' in the water phantom in absence of the ionization chamber can be expressed as

$$
D_{w}\left(Z_{r e f}\right)=P \cdot N_{D, W} \cdot \bar{D}_{\mathrm{det}}
$$

Where, $\mathrm{N}_{\mathrm{D}, \mathrm{w}}$ represents the calibration factor of the ionization chamber, $\bar{D}_{\text {det }}$ is the imparted to the air filled volume of the chamber, ' $\mathrm{P}$ ' be the perturbation coefficient which is the combination of the effects $\mathrm{P}_{\text {wall }}$ (correction factor for non-water equivalence of the chamber wall), $\mathrm{P}_{\text {cav }}$ (change of electron fluence related to the air cavity) and $\mathrm{P}_{\text {dis }}$ (the effect of volume of water with the detector cavity). Therefore, the equation (3) can be written as

$$
D_{w}\left(Z_{r e f}\right)=P\left(P_{\text {wall }} \cdot P_{c a v} \cdot P_{d i s}\right) \cdot N_{D, W} \cdot \bar{D}_{\mathrm{de}}
$$

The shifts of EPOM ' $\Delta Z$ ' for cylindrical chambers of photon beam are not only the function of cavity radius but also depends on the complex way on all construction details of the chamber such as chamber wall, cavity length, central electrode as well as the incoming photon energy. The shifting of effective point from the reference depth due to the perturbation with its component can be calculated by two different ways (i) Absolute dose measurement at reference depth by standard chamber whose effective point is known and then compare the measurement chamber placing the geometrical center at reference depth and (ii) compare the PDD or ionization curve data by reference chamber and unknown chamber. The effective point of measurement can be calculated by

$$
D_{w}\left(Z_{r e f}\right)=D_{w}\left(P_{e f f}\right)+D_{w}(\Delta r)
$$

Where, ' $\Delta r$ ' is the small change of shift of reference distance due to perturbation effect. From PDD curve, the shift of effective point of measurement can be obtained by the following equation

$$
\Delta r=d r=d_{P D D}^{c y l}-d_{P D D}^{\text {Murkus/ } p p c 40}
$$

For simply it can be expressed by

$$
d_{e f f}=d_{P D D(10)_{M u r k u s / P P C} 40}^{c y l}-10
$$

Where, $\boldsymbol{d}_{P D D(10)_{M u r k u s / P P C 40}^{c y l}}$ is the depth of the same percentage value taken from PDD at $10 \mathrm{~cm}$ depth dose obtained for the Murkus 23343/PPC 40 chamber. The analysis of depth dose ionization curve is obtained by MEPHYSTO software [8]. The shift is related with the chamber radius and termed as effective point of measurement (EPOM) which depends on the chamber volume. Various international protocol recommended for various constants value of shifts such as IAEA TRS protocol TRS 277 recommends $\Delta \mathrm{r}=0.75 \mathrm{r}$ for high energy X-ray beam [9], whereas TG-51 (AAPM protocol) and DIN-6800 protocol recommends for the shifts of $0.5 \mathrm{r}$ $[10,3]$. On the other hand, TRS-398 (IAEA) protocol recommends the shift of $0.6 \mathrm{r}$ for non-reference condition [4].

\section{Results and Discussion}

In our research, six ionization chambers have been calibrated at radiation qualities $\left({ }^{60} \mathrm{Co}\right)$ standard procedure set-forth by SSDL of Bangladesh Atomic Energy Commission. The chambers are calibrated against reference standard chamber NE2571-1205 
as well as traceable to NE2581-537, IAEA standard. The detail of the calibration factors obtained from this study is given in (Table 1). The calibration factor obtained from the present experiment is compared with the values of quoted by the manufacturer. It is seen that the deviation between manufacturer values and present measurement lies within $0 \%$ to $1.44 \%$ with a maximum uncertainty of $\pm 1.7 \%$. It is mentioned here that the manufacturer uncertainties were quoted as \pm 1.1 to $\pm 2.2 \%$.

Table 1: Calibration factors of the chambers at ${ }^{60} \mathrm{Co}$ radiation quality with manufacturer values.

\begin{tabular}{|c|c|c|c|c|c|c|}
\hline $\begin{array}{c}\text { Chamber type with } \\
\text { Sl. No. }\end{array}$ & $\begin{array}{l}\text { Chamber } \\
\text { Volume (cc) }\end{array}$ & $\begin{array}{l}\text { Present Measurement: } \\
\text { Absorbed dose to } \\
\text { Water Calibration } \\
\text { Factor (CF) } N_{D, w}(\mathrm{~Gy} / \mathrm{C})\end{array}$ & $\begin{array}{l}\text { Present value } \\
\text { of Uncertainty } \\
\qquad(k=1)\end{array}$ & $\begin{array}{c}\text { Manufacturer } \\
\text { Measurement: Absorbed } \\
\text { Dose to Water Calibration } \\
\left.\text { factor }(\mathrm{CF}), \mathrm{N}_{\mathrm{D}, \mathrm{w}}(\mathrm{Gy} / \mathrm{C})\right)\end{array}$ & $\begin{array}{c}\text { Stated } \\
\text { Uncertainty } \\
\text { Manufacturer } \\
(\mathrm{k}=1)\end{array}$ & $\begin{array}{c}\text { Deviation } \\
\text { (\%) }\end{array}$ \\
\hline PTW 30013-364 & 0.6 & $5.420 \times 10^{7}$ & $\pm 1.1 \%$ & $5.343 \times 10^{7}$ & $\pm 2.2 \%$ & 1.44 \\
\hline PTW 31010-2211 & 0.125 & $2.882 \times 10^{8}$ & $\pm 1.1 \%$ & $2.882 \times 10^{8}$ & $\pm 1.1 \%$ & 0 \\
\hline PTW 31010-1888 & 0.125 & $3.037 \times 10^{8}$ & $\pm 1.1 \%$ & $3.050 \times 10^{8}$ & $\pm 1.1 \%$ & 0.43 \\
\hline PTW 31014-1273 & 0.015 & $2.370 \times 10^{9}$ & $\pm 1.7 \%$ & $2.352 \times 10^{9}$ & $\pm 1.1 \%$ & 0.85 \\
\hline PTW 30013-4774 & 0.6 & $5.331 \times 10^{7}$ & $\pm 1.4 \%$ & $5.408 \times 10^{7}$ & $\pm 1.1 \%$ & 1.43 \\
\hline $\begin{array}{l}\text { Exradin A19- } \\
\text { XAQ110103 }\end{array}$ & 0.62 & $5.089 \times 10^{7}$ & $\pm 1.3 \%$ & $5.044 \times 10^{7}$ & $\pm 1.4 \%$ & 0.89 \\
\hline
\end{tabular}

Effective Point of Measurement (EPOM) of Ionization Chambers

In order to derive EPOM, the PDD curve was measured with reference plane parallel plate and cylindrical chamber for various depths $(100 \%, 80 \%$ and $50 \%)$ are summarized in (Tables $2-4$ ) respectively. PDD data are taken at energies 6, 15 and $10 \mathrm{MV}$ in various field sizes $(5 \mathrm{~cm} \times 5 \mathrm{~cm}$ to maximum $30 \mathrm{~cm} \times 30 \mathrm{~cm})$. The variation of PDD as a function of depth in water $(\mathrm{mm})$ for the $6 \mathrm{MV}, 15 \mathrm{MV}$ and $10 \mathrm{MV}$ photon beams for $10 \mathrm{~cm} \times 10 \mathrm{~cm}$ field size of different chamber are shown in Figures 1-3. From the figures it is seen that build-up region increases with photon energies.

Table 2: PDD data for PTW 30013-364 and FC 65G cylindrical chambers with respect to reference PPC 40 chamber for various depths in water phantom at different field size for $6 \mathrm{MV}$ photon beam.

\begin{tabular}{|c|c|c|c|c|c|c|}
\hline \multirow{2}{*}{ Chamber Type } & \multirow{2}{*}{ PDD (\%) } & \multicolumn{5}{|c|}{ Depth for different field sizes $(\mathrm{cm} \times \mathrm{cm})$} \\
\hline & & $5 \times 5$ & $10 \times 10$ & $15 \times 15$ & $20 \times 20$ & $25 \times 25$ \\
\hline \multirow{3}{*}{ PPC 40-1592 } & 100 & 15.8 & 13.8 & 11.8 & 11.8 & 11.8 \\
\hline & 80 & 58.5 & 64.2 & 66.3 & 68.3 & 68.6 \\
\hline & 50 & 137 & 150.5 & 158.8 & 165.1 & 168.4 \\
\hline \multirow{3}{*}{ PTW 30013-364 } & 100 & 15.8 & 15.8 & 15.8 & 15.8 & 11.8 \\
\hline & 80 & 59.3 & 65.5 & 68.8 & 69.2 & 71.4 \\
\hline & 50 & 136.7 & 152 & 161.5 & 164.4 & 171.2 \\
\hline \multirow{3}{*}{ FC 65G-3320 } & 100 & 15.8 & 15.8 & 15.8 & 15.8 & 13.85 \\
\hline & 80 & 59.6 & 65.3 & 69.1 & 70.1 & 73.2 \\
\hline & 50 & 137.9 & 151.6 & 161.5 & 167.6 & 176.4 \\
\hline
\end{tabular}

Table 3: PDD data for FC 65G cylindrical chamber with respect to reference PPC 40 chamber for various depths in water phantom at different field size for 15MV photon beam.

\begin{tabular}{|c|c|c|c|c|c|c|}
\hline \multirow{2}{*}{ Chamber Type } & \multirow{2}{*}{ PDD (\%) } & \multicolumn{5}{|c|}{ Depth for different field sizes $(\mathrm{cm} \times \mathrm{cm})$} \\
\hline & & $5 \times 5$ & $10 \times 10$ & $15 \times 15$ & $20 \times 20$ & $25 \times 25$ \\
\hline \multirow{3}{*}{ PPC 40-1592 } & 100 & 31.5 & 27.5 & 25.5 & 23.5 & 23.5 \\
\hline & 80 & 89.5 & 89.5 & 88.8 & 88.9 & 89.1 \\
\hline & 50 & 191.5 & 197.5 & 202.5 & 204.5 & 209 \\
\hline \multirow{3}{*}{ FC 65G-3320 } & 100 & 30.5 & 27.5 & 25.5 & 23.5 & 23.5 \\
\hline & 80 & 87.3 & 90.5 & 90.5 & 89.8 & 91.2 \\
\hline & 50 & 188 & 199 & 204 & 208 & 212 \\
\hline
\end{tabular}


Table 4: PDD data for Semiflex 31010 with respect to reference chamber Murkus 23343 for various depths at various field size for $6 \mathrm{MV}$ and $10 \mathrm{MV}$ photon beam.

\begin{tabular}{|c|c|c|c|c|c|c|c|c|}
\hline \multirow{2}{*}{$\begin{array}{l}\text { Chamber } \\
\text { Type }\end{array}$} & \multirow{2}{*}{$\begin{array}{c}\text { Photon beam } \\
\text { (MV) }\end{array}$} & \multirow{2}{*}{ PDD (\%) } & \multicolumn{6}{|c|}{ Depth for different field sizes $\left(\mathrm{cm}^{2}\right)$} \\
\hline & & & $5 \times 5$ & $10 \times 10$ & $15 \times 15$ & $20 \times 20$ & $25 \times 25$ & $30 \times 30$ \\
\hline \multirow{6}{*}{ Murkus 23343} & \multirow{3}{*}{6} & 100 & 14 & 14 & 12 & 12 & 11 & 11 \\
\hline & & 80 & 58.4 & 65.8 & 66.84 & 67.8 & 70.3 & 70.9 \\
\hline & & 50 & 137 & 151.4 & 160 & 165.4 & 171.2 & 171.1 \\
\hline & \multirow{3}{*}{10} & 100 & 24.75 & 22.5 & 21 & 19.5 & 20.25 & 19.5 \\
\hline & & 80 & 78.3 & 80 & 82.4 & 83.3 & 85.3 & 86.1 \\
\hline & & 50 & 173.2 & 182.7 & 190 & 196 & 200.8 & 204 \\
\hline \multirow{6}{*}{$\begin{array}{c}\text { Semiflex } \\
31010\end{array}$} & \multirow{3}{*}{6} & 100 & 16 & 16 & 14 & 15 & 15 & 15 \\
\hline & & 80 & 61.7 & 68.6 & 68.7 & 74.2 & 73.4 & 74.5 \\
\hline & & 50 & 144 & 153.2 & 162.5 & 169.6 & 179.2 & 178.3 \\
\hline & \multirow{3}{*}{10} & 100 & 25.5 & 22.5 & 21 & 24 & 23 & 23 \\
\hline & & 80 & 78.6 & 83.1 & 83.8 & 88.8 & 87.5 & 87.5 \\
\hline & & 50 & 173.5 & 185 & 192.5 & 198.5 & 200 & 203 \\
\hline
\end{tabular}

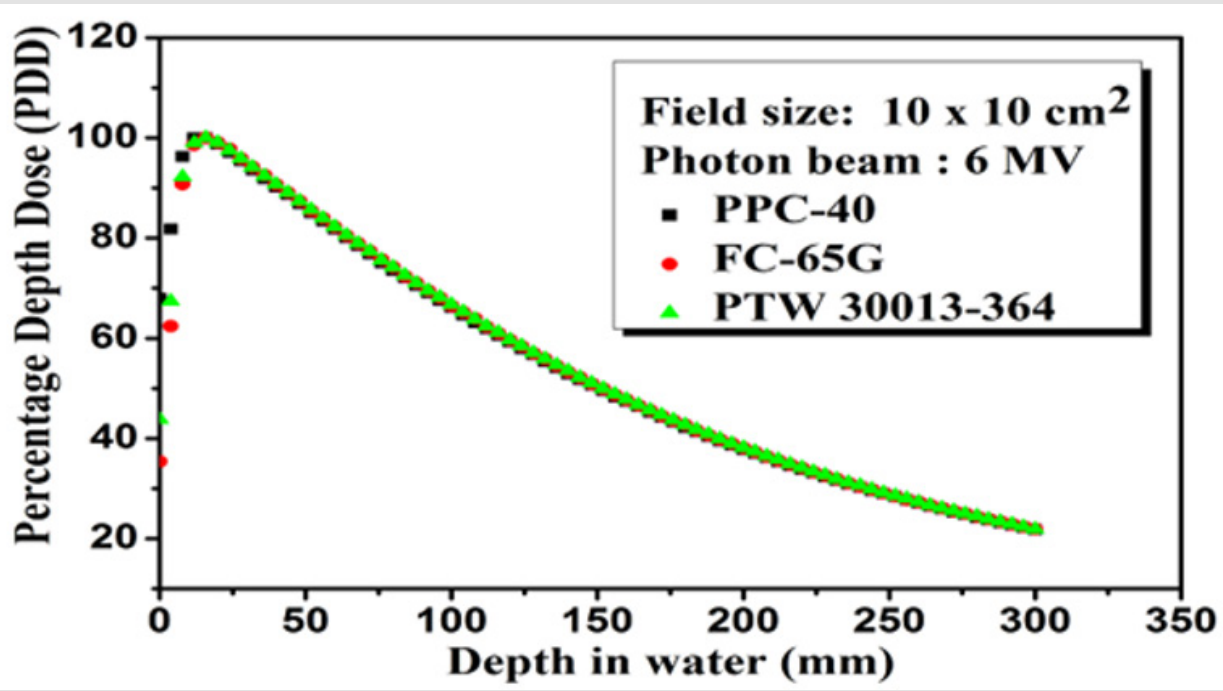

Figure 1: PDD curves for 6 MV photon beams of field size $10 \mathrm{~cm} \times 10 \mathrm{~cm}$ at $100 \mathrm{~cm}$ depth for PPC 40, FC 65G and PTW $30013-364$ chambers.

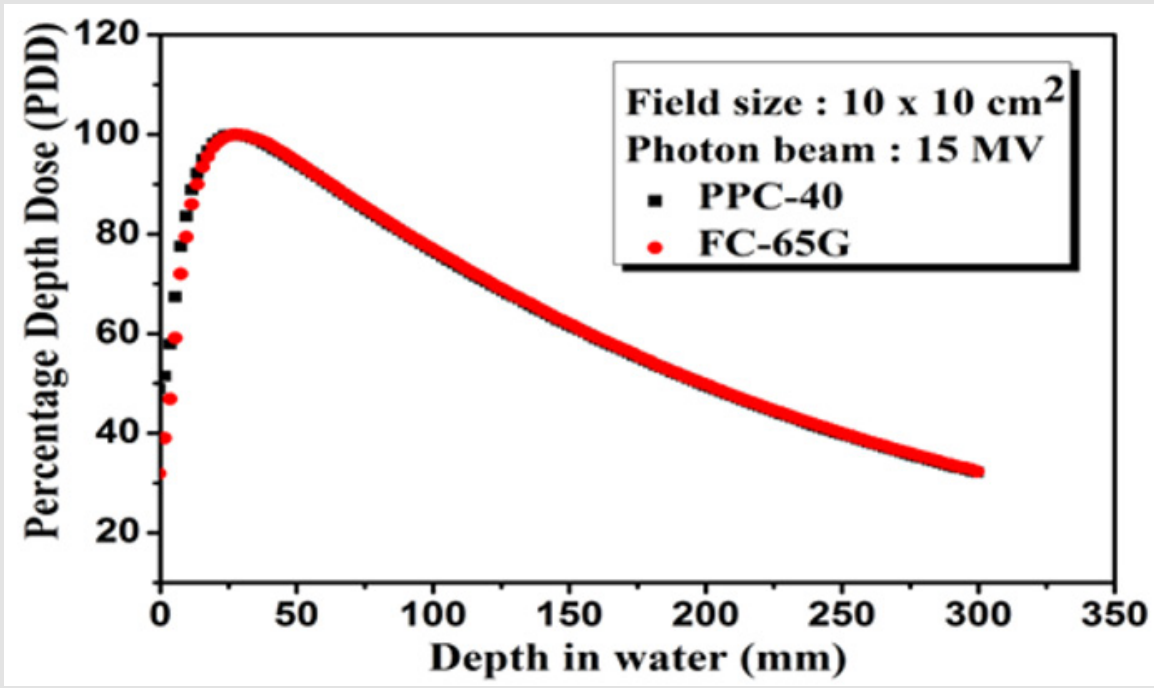

Figure 2: PDD curves for $15 \mathrm{MV}$ photon beams of field size $10 \mathrm{~cm} \times 10 \mathrm{~cm}$ at $100 \mathrm{~cm}$ depth for PPC 40 and FC $65 \mathrm{G}$ chambers. 


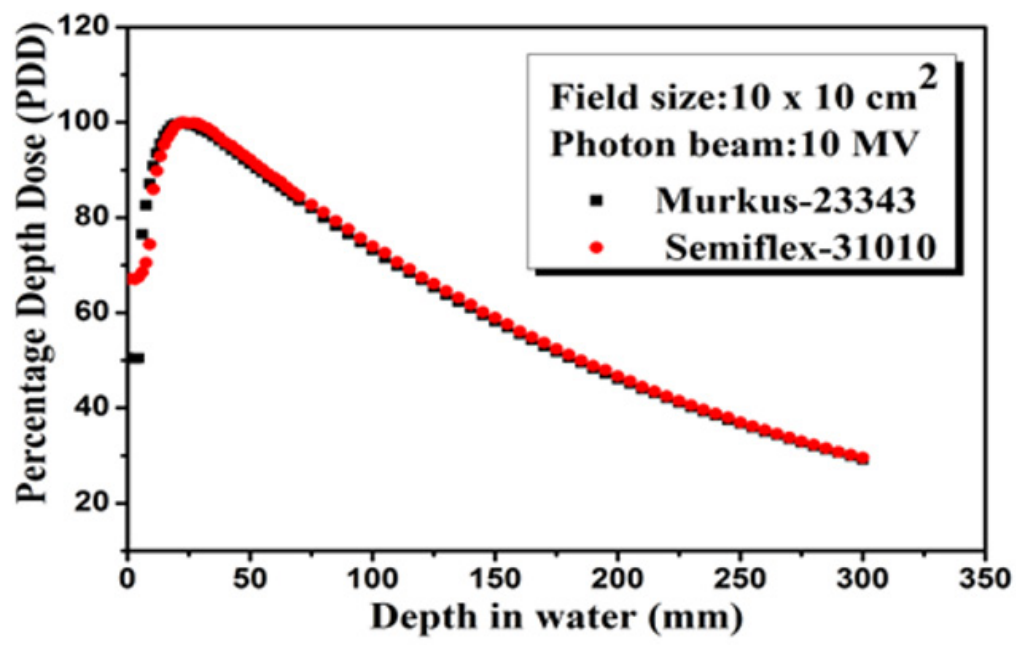

Figure 3: PDD curves for $10 \mathrm{MV}$ photon beams of field size $10 \mathrm{~cm} \times 10 \mathrm{~cm}$ at $100 \mathrm{~cm}$ depth for Murkus 23343 , Semiflex 31010 chambers.

\section{Determination of Effective Shift}

The distance between the central axis and the EPOM is termed as effective shift or EPOM shift. It is generally assumed that the displacement effect is almost constant beyond the maximum. Therefore, a fixed EPOM is used throughout the depth profile. This assumption allows normalizing depth profiles to the maximum and using PDDs to determine the EPOM. Here the PPC 40 and Murkus 23343 whose effective points are known were used as a reference. The shift between the reference point (geometrical point) of the chambers and the EPOM was determined at different depth at different field size $(5 \mathrm{~cm} \times 5 \mathrm{~cm}$ to maximum $30 \mathrm{~cm} \times 30 \mathrm{~cm})$ for $6 \mathrm{MV}$, $10 \mathrm{MV}$ and $15 \mathrm{MV}$ photon beam and for $100 \%, 80 \%$ and $50 \%$ PDD values are shown in the following (Tables 5-7) respectively. The IAEA protocol TRS-398 recommends the displacement correction of EPOM by a shift of $0.6 \mathrm{r}$ for non-reference condition [4]. The recommended values are valid for photon energies only. In this study, EPOM values are measured for both reference and nonreference conditions.

Table 5: Effective shift of chamber FC 65G and PTW 30013-364 with respect to PPC 40 for 6MV photon beam.

\begin{tabular}{|c|c|c|c|c|c|c|c|}
\hline \multirow{2}{*}{$\begin{array}{l}\text { Photon Energy } \\
\text { (MV) }\end{array}$} & \multirow{2}{*}{$\begin{array}{c}\text { Chamber Model } \\
\text { and Sl. No. }\end{array}$} & \multirow{2}{*}{ PDD (\%) } & \multicolumn{5}{|c|}{ Effective Shift for different field sizes $\left(\mathrm{cm}^{2}\right)$} \\
\hline & & & $5 \times 5$ & $10 \times 10$ & $15 \times 15$ & $20 \times 20$ & $25 \times 25$ \\
\hline \multirow{6}{*}{6} & \multirow{3}{*}{ PTW 30013-364 } & 100 & $0 r^{*}$ & $0.64 \mathrm{r}$ & $1.29 \mathrm{r}$ & $1.29 \mathrm{r}$ & Or \\
\hline & & 80 & $0.25 \mathrm{r}$ & $0.42 \mathrm{r}$ & $0.81 \mathrm{r}$ & $0.29 \mathrm{r}$ & $0.90 \mathrm{r}$ \\
\hline & & 50 & $0.09 \mathrm{r}$ & $0.48 \mathrm{r}$ & $0.87 \mathrm{r}$ & $0.23 \mathrm{r}$ & $0.90 \mathrm{r}$ \\
\hline & \multirow{3}{*}{ FC65 G-3320 } & 100 & or & $0.65 \mathrm{r}$ & $1.29 \mathrm{r}$ & $1.29 \mathrm{r}$ & $0.66 \mathrm{r}$ \\
\hline & & 80 & $0.35 \mathrm{r}$ & $0.35 \mathrm{r}$ & $0.90 \mathrm{r}$ & $0.58 \mathrm{r}$ & $1.48 \mathrm{r}$ \\
\hline & & 50 & $0.29 \mathrm{r}$ & $0.45 \mathrm{r}$ & $0.87 \mathrm{r}$ & $0.81 \mathrm{r}$ & $2.58 \mathrm{r}$ \\
\hline
\end{tabular}

Note: ${ }^{*} \mathrm{r}$ is the radius of the chamber

Table 6: Effective shift of chamber Semiflex 31010 with respect to Murkus 23343 for 6MV and 10MV photon beam.

\begin{tabular}{|c|c|c|c|c|c|c|c|c|}
\hline \multirow{2}{*}{$\begin{array}{l}\text { Chamber } \\
\text { Model and } \\
\text { Sl. No. }\end{array}$} & \multirow{2}{*}{$\begin{array}{c}\text { Photon beam } \\
\text { (MV) }\end{array}$} & \multirow{2}{*}{ PDD (\%) } & \multicolumn{6}{|c|}{ Effective shift for different field sizes $\left(\mathrm{cm}^{2}\right)$} \\
\hline & & & $5 \times 5$ & $10 \times 10$ & $15 \times 15$ & $20 \times 20$ & $25 \times 25$ & $30 \times 30$ \\
\hline \multirow{6}{*}{$\begin{array}{c}\text { Semiflex } \\
31010-1217\end{array}$} & \multirow{3}{*}{6} & 100 & $0.73 r^{*}$ & $0.73 \mathrm{r}$ & $0.73 \mathrm{r}$ & $1.09 \mathrm{r}$ & $1.45 \mathrm{r}$ & $1.45 \mathrm{r}$ \\
\hline & & 80 & $1.20 \mathrm{r}$ & $1.02 \mathrm{r}$ & $0.68 \mathrm{r}$ & $2.32 \mathrm{r}$ & $1.13 \mathrm{r}$ & $1.31 \mathrm{r}$ \\
\hline & & 50 & $2.55 \mathrm{r}$ & $0.65 r$ & $0.91 \mathrm{r}$ & $1.53 \mathrm{r}$ & $2.91 \mathrm{r}$ & $2.62 \mathrm{r}$ \\
\hline & \multirow{3}{*}{10} & 100 & $0.27 \mathrm{r}$ & or & or & $1.64 \mathrm{r}$ & $1.00 \mathrm{r}$ & $1.27 \mathrm{r}$ \\
\hline & & 80 & $0.11 \mathrm{r}$ & $1.13 \mathrm{r}$ & $0.51 \mathrm{r}$ & $2.00 \mathrm{r}$ & $0.80 \mathrm{r}$ & $0.51 \mathrm{r}$ \\
\hline & & 50 & $0.11 \mathrm{r}$ & $0.83 r$ & $0.91 \mathrm{r}$ & $0.91 \mathrm{r}$ & $0.29 \mathrm{r}$ & $0.36 \mathrm{r}$ \\
\hline
\end{tabular}

Note: * $\mathrm{r}$ is the radius of the chamber 
Table 7: Effective shift of chamber FC 65G-3320with respect to PPC 40 for 15MV photon beam.

\begin{tabular}{|c|c|c|c|c|c|c|c|}
\hline \multirow{2}{*}{$\begin{array}{c}\text { Chamber Model } \\
\text { and Sl. No. }\end{array}$} & \multirow{2}{*}{$\begin{array}{l}\text { Photon beam } \\
\text { (MV) }\end{array}$} & \multirow{2}{*}{ PDD (\%) } & \multicolumn{5}{|c|}{ Effective shift for different field sizes $\left(\mathrm{cm}^{2}\right)$} \\
\hline & & & $5 \times 5$ & $10 \times 10$ & $15 \times 15$ & $20 \times 20$ & $25 \times 25$ \\
\hline \multirow{3}{*}{ FC 65 G-3320 } & \multirow{3}{*}{15} & 100 & 100 & $0.30 r^{*}$ & Or & Or & Or \\
\hline & & 80 & 80 & $0.67 \mathrm{r}$ & $0.30 \mathrm{r}$ & $0.52 \mathrm{r}$ & $0.27 \mathrm{r}$ \\
\hline & & 50 & 50 & $1.06 r$ & $0.45 r$ & $0.45 \mathrm{r}$ & $1.06 \mathrm{r}$ \\
\hline
\end{tabular}

Note: *r is the radius of the chamber

From (Tables 5-7), it is seen that in case of reference condition $(10 \mathrm{~cm} \times 10 \mathrm{~cm}$ field size, $100 \mathrm{~cm}$ SSD, $10 \mathrm{~cm}$ depth in water $)$ the shift of the effective point of the chambers PTW 30013, FC 65G and Semiflex 31010 are found $0.64 \mathrm{r}, 0.65 \mathrm{r}$, and $0.73 \mathrm{r}$ respectively for $6 \mathrm{MV}$ photon beam. Whereas at $10 \mathrm{MV}$, the the shift of Semiflex 31010 chambers is found 0 . The shift of effective point increases with depth in water. Some exception also found in this study that might be due to the uncertainty in the measurement system. It must be noted that for photon beam, the total uncertainty in the measurement of absorbed dose to water for chambers are lies between $\pm 1.1 \%$ to $\pm 1.7 \%$, whereas, the total uncertainty for effective point of measurement is found from $\pm 0.6 \%$ to $\pm 0.7 \%$. It is also seen that for FC $65 \mathrm{G}$ chamber, the shift of effective point is 0 at higher energy $15 \mathrm{MV}$ which might be due the chamber wall material (graphite which is water equivalent).

\section{Conclusion}

For accurate dosimetry planning and to reduce the uncertainty of dosimetry data used by the radiotherapy centres, the effective point plays an important role. The experimental results generally demonstrate that the position of $\mathrm{P}_{\text {eff }}$ in the depth of water phantom of cylindrical ionization chambers cannot be described by a constant shift from the central axis. It is mentioned here that the current dosimetry protocols suggested the shift of effective point by a constant value of $0.6 \mathrm{r}$ ( $\mathrm{r}$ being the radius of ionization chamber). From our work, it was found that the observed deviation does not always remain constant at the value of $0.6 \mathrm{r}$ and varies with different field size, depth and energy. The application of the proposed effective point of measurement from this study will increase the accuracy in calculating absolute depth dose data from measured depth ionization curves, especially for depth beyond the reference depth. Absorbed dose to water calibration coefficient $\left(\mathrm{N}_{\mathrm{D}, \mathrm{w}}\right)$ of different chambers were compared with the supplied values by the manufacturer and found good in agreement and within $\pm 1.4 \%$ with maximum uncertainty of $\pm 1.7 \%$ (coverage factor $\mathrm{k}=1$ ) lies within the acceptance limit set-forth by IAEA $( \pm 1.5 \%)$. So, it is not reasonable to rely on the stability of calibration coefficient; rather it is mandatory to calibrate the ionization chamber once a year to be used in dosimetry and QA purposes in radiotherapy.

\section{References}

1. Seif F, Karbalayi M, Bayatiani MR, Karbalayi M, Tahmasebi Birgani MJ (2013) Effective Point of Measurement in Cylindrical Ion Chamber for Megavoltage Photon Beams. Iran Journal of Medical Physics 10(3): 147155.

2. Legrand C, Hartmann GH, Karger CP (2012) Experimental determination of the effective point of measurement for cylindrical ionization chambers in ${ }^{60} \mathrm{Co}$ gamma radiation. Phys Med Biol 57: 3463-3475.

3. Deutsches Institut Fur Normung EV (2008) DIN 6800-2.

4. (2004) IAEA International Atomic Energy Agency, Absorbed Dose Determination in External Beam Radiotherapy: An International Code of Practice for Dosimetry Based on Standards of Absorbed Dose to Water. IAEA Technical Report Series No 398 International Atomic Energy Agency, Vienna.

5. Kawrakow I (2006) On the effective point of measurement in megavoltage photon beams. Med Phys 33(6): 1829-1839.

6. Tessier F, Kawrakow I (2010) Effective point of measurement of thimble ion chambers in megavoltage photon beams. Med Phys 37(1): 96-107.

7. Tessier F, Hooten BD, Mc Ewen MR (2010) Zero-shift thimble ionization chamber. Med Phys 37(3): 1161-1163.

8. (2012) PTW Freiburg GmbH, Relative Dosimetry, Water tanks, Beam Commissioning. MEPHYSTO mc2.

9. (1998) IAEA Technical Report Series No 277, International Atomic Energy Agency. Vienna.

10. Almond PR, Biggs PJ, Coursey BM, Hanson WF, Huq MS, et al. (1999) AAPM's TG-51 protocol for clinical reference dosimetry of high-energy photon and electron beams. Med Phys 26: 1847-1870.
ISSN: 2574-1241

DOI: 10.26717/BJSTR.2019.21.003539

Md Shakilur Rahman. Biomed J Sci \& Tech Res

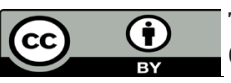

This work is licensed under Creative

Commons Attribution 4.0 License

Submission Link: https://biomedres.us/submit-manuscript.php

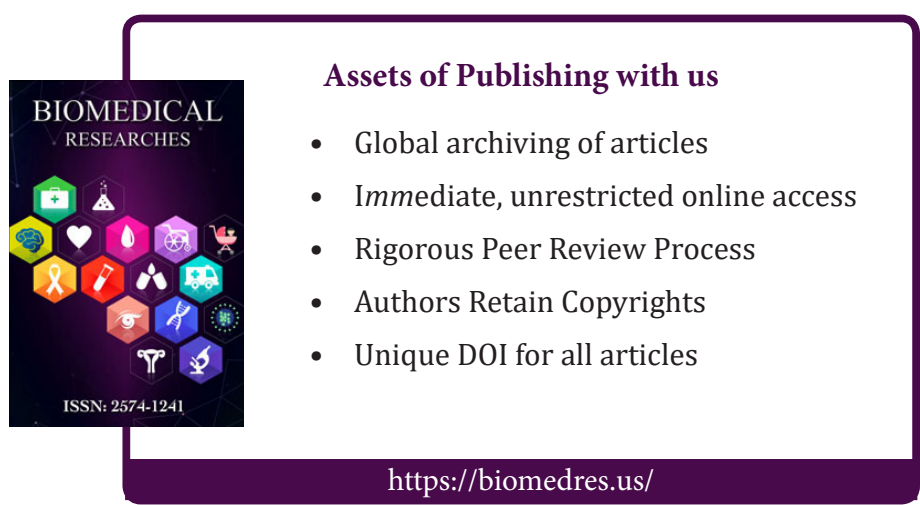

